\title{
CIÊNCIA COM CONSCIÊNCIA
}

Edgard Morin. Mem. Martins: Publicações Europa-América, s. d., 268p.

A ciência não é somente uma acumulação de verdades verdadeiras. Digamos mais, continuando Popper: é um campo sempre aberto onde se combatem não só as teorias mas também os princípios da explicação, isto é, também as visões de mundo e os postulados metafísicos. (p. 20)
O conhecimento científico não é o reflexo das leis da natureza. Traz com ele um universo de teorias, de idéias, de paradigmas, o que nos remete, por um lado, para as condições bioantropológicas do conhecimento (porque não há espírito sem cérebro), por outro lado, para o enraizamento cultural, social, histórico das teorias. (p. 21)

É, pois, necessário que toda a ciência se interrogue sobre as suas estruturas ideológicas e o seu enraizamento sociocultural. Aqui, damo-nos conta de que nos falta uma ciência capital, a ciência das coisas do espírito ou noologia, capaz de conceber como e em que condições culturais as idéias se agrupam, se encadeiam, se ajustam umas às outras, constituem sistemas que se auto-regulam, se autodefendem, se automultiplicam, se autoprogramam. Falta-nos uma sociologia do conhecimento científico que seja não só poderosa mas também mais complexa que a ciência que examina. (p. 21)

\section{COMPLEXIDADE}

\section{A problemática da complexidade} permanece marginal. Tanto no pensamento científico como no pensamento epistemológico como no pensamento filosófico ...

Curiosamente, a complexidade só apareceu numa linha marginal entre o engineering e a ciência, na cibernética, a teoria dos

sistemas. ... Como a complexidade só foi tratada marginalmente, ou por autores marginais, como eu próprio, ela suscita necessariamente malentendidos fundamentais. (p. 137)
O primeiro mal-entendido consiste em conceber a complexidade como receita, como resposta, em vez de a considerar como desafio e como incitamento para pensar; acredita-se ... que a complexidade deve ser um substituto eficaz da simplificação, ... que vai permitir programar e esclarecer. Ou ... concebe-se a complexidade como inimiga da ordem e da clareza. (p. 137)
O segundo mal-entendido consiste em confundir a complexidade e a completidão. ... O problema da complexidade não é o de estar completo, mas sim do incompleto do conhecimento. ... o pensamento complexo tenta ter em linha de conta aquilo de que se desembaraçam, excluindo-o, os tipos mutiladores de pensamento a que chamo simplificadores e, portanto, ela luta não contra o incompleto mas sim contra a mutilação. (p. 138) 
Se tentarmos pensar o fato de que somos seres simultaneamente físicos, biológicos, sociais, culturais, psíquicos $e$ espirituais, é evidente que a complexidade reside no fato de se tentar conceber a articulação, a identidade e a diferença entre todos estes aspectos, enquanto o pensamento simplificador ou separa estes diferentes aspectos ou os unifica através de uma redução mutiladora. (p. 138)
Não é possível chegar à complexidade através de uma definição prévia; é-nos necessário seguir caminhos de tal forma diversos que podemos perguntar a nós próprios se há complexidades e não uma complexidade. (p. 138)

A ambição da complexidade é relatar articulações que são destruídas pelos cortes entre disciplinas, entre categorias cognitivas e entre tipos de conhecimento. De fato, a aspiração à complexidade tende para o conhecimento multidimensional. Não se trata de dar todas as informações sobre um fenômeno estudado, mas de respeitar as suas diversas dimensões; (p. 138)

Devo, pois, indicar previamente e de uma forma não complexa as diferentes avenidas que conduzem ao 'desafio da complexidade'. (p. 139)

\section{DESAFIO DA COMPLEXIDADE}

A segunda avenida da complexidade é a transgressão, nas ciências naturais, dos limites daquilo a que poderia chamar-se a abstração universalista que eliminava a singularidade, a localização e a temporalidade. Assim, a biologia atual já não concebe de

¿ forma nenhuma a espécie como um

quadro geral do qual o indivíduo é um

N caso singular. Ela concebe a espécie

viva como uma singularidade que

produz singularidades. A própria vida

é uma organização singular entre os

tipos existentes de

organização físico-

química. (p. 139)
A terceira avenida é a da complicação. O problema da complicação surgiu a partir do momento em que se viu que os fenômenos biológicos e sociais apresentavam um número incalculável de interações, de inter-retroações, um fabuloso enredo que não podia ser informatizado nem mesmo pelo computador mais poderoso, donde o paradoxo de Niels Bohr que diz: 'As interações que mantêm em vida o organismo de um cão são as que é impossível estudar in vivo. Para as estudar corretamente, seria necessário matar o cão'. (p. 140)
A primeira avenida, $o$ primeiro caminho é o da $\sum$ irredutibilidade do acaso ou da desordem. O acaso e a desordem brotaram no universo das ciências físicas inicialmente com a irrupção do calor, que é agitaçãocolisão-dispersão dos átomos ou moléculas; depois com a irrupção das indeterminações microfísicas, e, finalmente, na explosão originária e na dispersão atual do cosmos. (p. 139). 
A quarta avenida abriu-se quando se começou a conceber uma misteriosa relação complementar $e$, contudo, logicamente antagônica entre as noções de ordem, de desordem e de organização. É mesmo esse o princípio 'order from noise', formulado por Heinz von Foerster em 1959, que se opunha ao princípio clássico 'order from order'. O princípio 'order from noise' significa que fenômenos ordenados (eu diria organizados) podem nascer de uma agitação ou de uma turbulência desordenada. Assim, os trabalhos de Prigogine mostraram que estruturas em turbilhão coerentes podiam nascer de perturbações que deveriam aparentemente resolver-se em turbulências. É neste sentido que emerge perante o nosso entendimento o problema de uma relação misteriosa entre a ordem, a desordem e a organização. (p. 140)

Outro princípio de complexidade (a sexta avenida) é o princípio da organização recursiva. A organização recursiva é a organização cujos efeitos e produtos são necessários à sua própria provocação de efeito e à sua própria produção. Trata-se rigorosamente do problema da autoprodução e da autoorganização. Assim, uma sociedade é produzida pelas interações entre indivíduos, mas estas interações produzem um todo organizador, o qual retroatua sobre os indivíduos para os co-produzir na sua qualidade de indivíduos humanos, o que eles não seriam se não dispusessem da educação, da linguagem e da cultura. Assim, o processo social é um elo produtivo ininterrupto em que, de alguma forma, os produtos são necessários à produção do que os produz. (p. 142)

\section{AUTOPRODUÇÃO}

LIVROS

\section{ORDEM/DESORDEM/ORGANIZAÇÃO}

A quinta avenida da complexidade é a da organização. Aqui surge uma dificuldade lógica; a organização é o que constitui um sistema a partir de elementos diferentes; nela constitui, portanto, uma unidade e, simultaneamente, uma multiplicidade. A complexidade lógica da unitas multiplex exige-nos que não dissolvamos o múltiplo no uno, nem o uno no múltiplo. (p. 140)

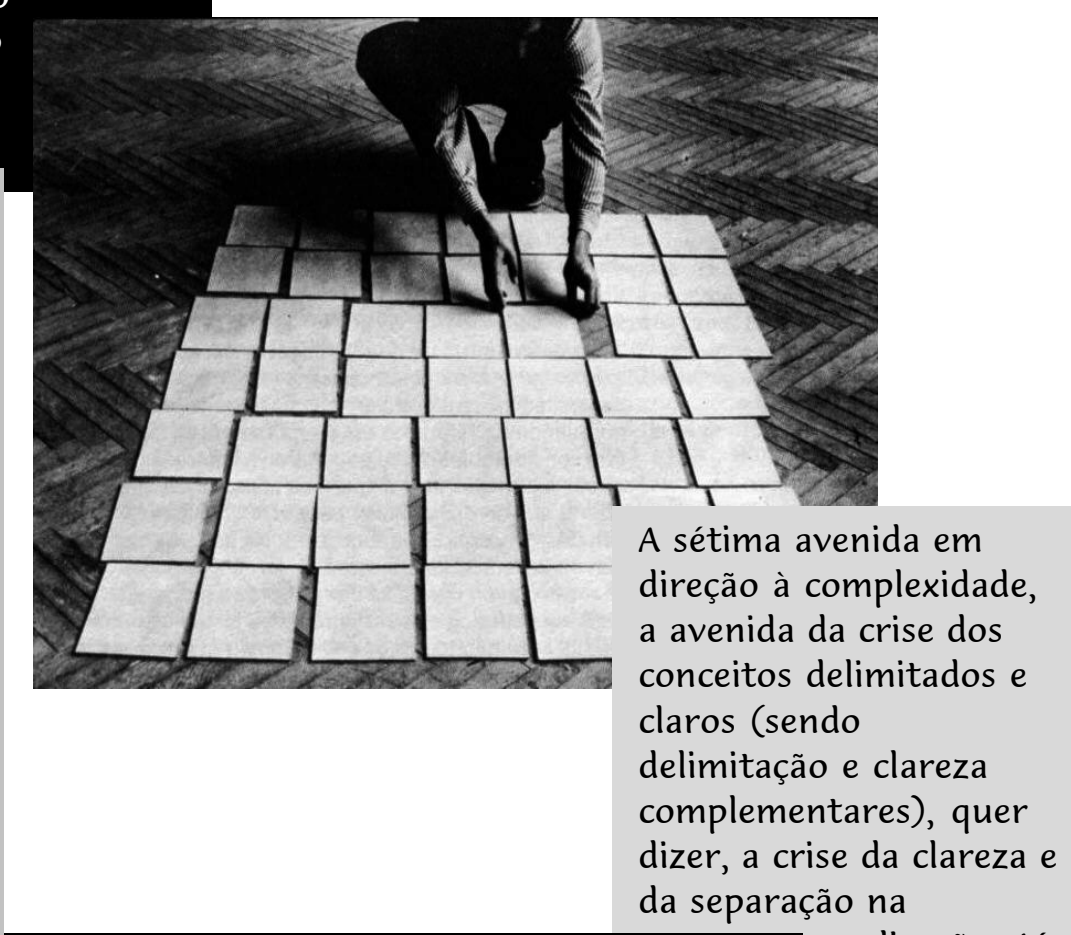

De qualquer forma, a complexidade surge como dificuldade, como incerteza e não como clareza e como resposta.

... Vemos atualmente que existe uma crise da explicação simples nas ciências biológicas e físicas: desde então, o que pareciam ser os resíduos não científicos das ciências humanas, a incerteza, a desordem, a contradição, a pluralidade, a complicação etc., fazem hoje parte de uma problemática geral do conhecimento científico. (p. 138) explicação. Aí, efetivamente, há ruptura com a grande idéia cartesiana de que a clareza e a distinção das idéias são um sinal da sua verdade, isto é, que não pode haver verdade que não possa ser expressa de forma clara e nítida. (p. 143) 
A oitava avenida da complexidade é o retorno do observador à sua observação. Nas ciências sociais, era de uma forma absolutamente ilusória que se julgava eliminar o observador. O sociólogo não está apenas na sociedade; de acordo com a concepção hologramática, a sociedade também está nele; ele está possuído pela cultura que possui. ... O observadorconceptor deve integrar-se na sua observação e na sua concepção. Deve tentar conceber o seu hic et nunc sociocultural. ... O problema do observador não se limita às ciências antropossociais; doravante, diz respeito às ciências físicas; de forma que o observador perturba a observação microfísica (Heisenberg). (p. 144)

\begin{tabular}{|c|}
\hline Certeza/Incerteza \\
\hline $\begin{array}{l}\text { A complexidade parece } \\
\text { negativa ou regressiva, visto } \\
\text { que é a reintrodução da } \\
\text { incerteza num conhecimento } \\
\text { que tinha partido em triunfo à conquista } \\
\text { da certeza absoluta. É preciso pôr luto por } \\
\text { este absoluto. Mas o aspecto positivo, o } \\
\text { aspecto progressivo que pode dar a } \\
\text { resposta ao desafio da complexidade é o } \\
\text { ponto de partida para um pensamento } \\
\text { multidimensional. (p. } 147 \text { ) }\end{array}$ \\
\hline $\begin{array}{l}\text { É necessário, por fim e especialmente, } \\
\text { encontrar o caminho de um pensamento } \\
\text { dialógico. (p. 147) }\end{array}$ \\
\hline $\begin{array}{l}\text {... significa que duas lógicas, dois princípios } \\
\text { estão unidos sem que a dualidade se perca } \\
\text { nesta unidade. (p. 148) }\end{array}$ \\
\hline
\end{tabular}

As diversas complexidades que evoquei (a complicação, a desordem, a contradição, a dificuldade lógica, os problemas da organização etc.), tudo isto tece a complexidade: complexus é o que é tecido em conjunto; é o tecido obtido a partir de fios diferentes e que se transformaram num só. Por outras palavras, tudo isso se cruza e volta a cruzar, se tece e volta a tecer, para formar a unidade da complexidade; mas a unidade do complexus não destrói a variedade nem a diversidade das complexidades que a teceram. (p. 147)

\section{VERDADE ABSOLUTA/}

A tudo isso acresce um problema-chave, que é o problema da contradição. A lógica clássica tinha valor de verdade absoluta e geral $e$, desde que se chegasse a uma contradição, o pensamento devia fazer marcha atrás; a contradição era o sinal de alarme que indicava o erro. Ora, Bohr notou, a meu ver, um acontecimento de importância epistemológica fundamental quando, não por fadiga mas por consciência dos limites da lógica, suspendeu o grande jogo entre a concepção corpuscular e a concepção ondulatória da partícula, declarando que era necessário aceitar a contradição entre as duas noções tornadas complementares, visto que as experiências levavam racionalmente a esta contradição. (p. 145-146) 


\section{Empirismo/Racionalismo}

A própria ciência obedece à dialógica. ... Caminha com a pata do empirismo e com a pata da racionalidade, com a da imaginação e com a da verificação. Ora, há sempre dualidade e conflito entre as visões empíricas que, em última análise, são puramente pragmáticas $e$ as visões racionalistas que, em última análise, se tornam racionalizadoras e lançam para fora da realidade o que escapa à sua sistematização. Assim, racionalidade e empirismo mantêm uma dialógica fecunda entre a vontade da razão de agarrar todo o real e a resistência do real à razão. Ao mesmo tempo, existem complementaridade e antagonismo entre a imaginação que faz as hipóteses e a verificação que as seleciona. Por outras palavras, a ciência fundamenta-se na dialógica entre a imaginação $e$ verificação, empirismo e racionalismo. (p. 148)

\section{CONFLITO}

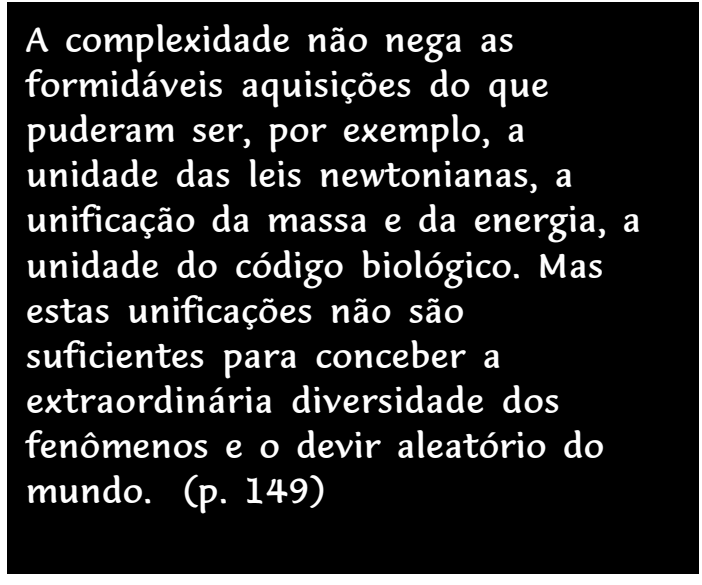

\section{ESTRATÉGIA}

O problema da complexidade não é formular programas que os espíritos podem instalar no seu computador mental. .. A complexidade faz apelo à estratégia. Só a estratégia pode ajudar a avançar no incerto e no aleatório. ... A estratégia é a arte de utilizar as informações que surgem durante a ação, integrá-las, formular subitamente esquemas de ação e ser capaz de reunir o máximo de certezas para defrontar o incerto. (p. 149)

O imperativo da complexidade, neste sentido, é a utilização estratégica daquilo a que chamo dialógica. ... (p. 150)

\section{Parte/Todo}

O princípio dialógico

é ... o confronto

com a dificuldade

do combate com o

real. Ao princípio

dialógico deve

juntar-se o princípio

hologramático, em

que, de certa forma, como num

holograma, o todo

está na parte que

está no todo. Assim, de alguma maneira, a totalidade da nossa informação genética está em cada uma das nossas células e a sociedade enquanto 'todo' está presente nos nossos espíritos

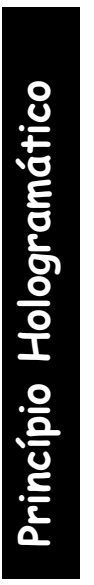
via a cultura que nos formou $e$ informou. (p. 148) 


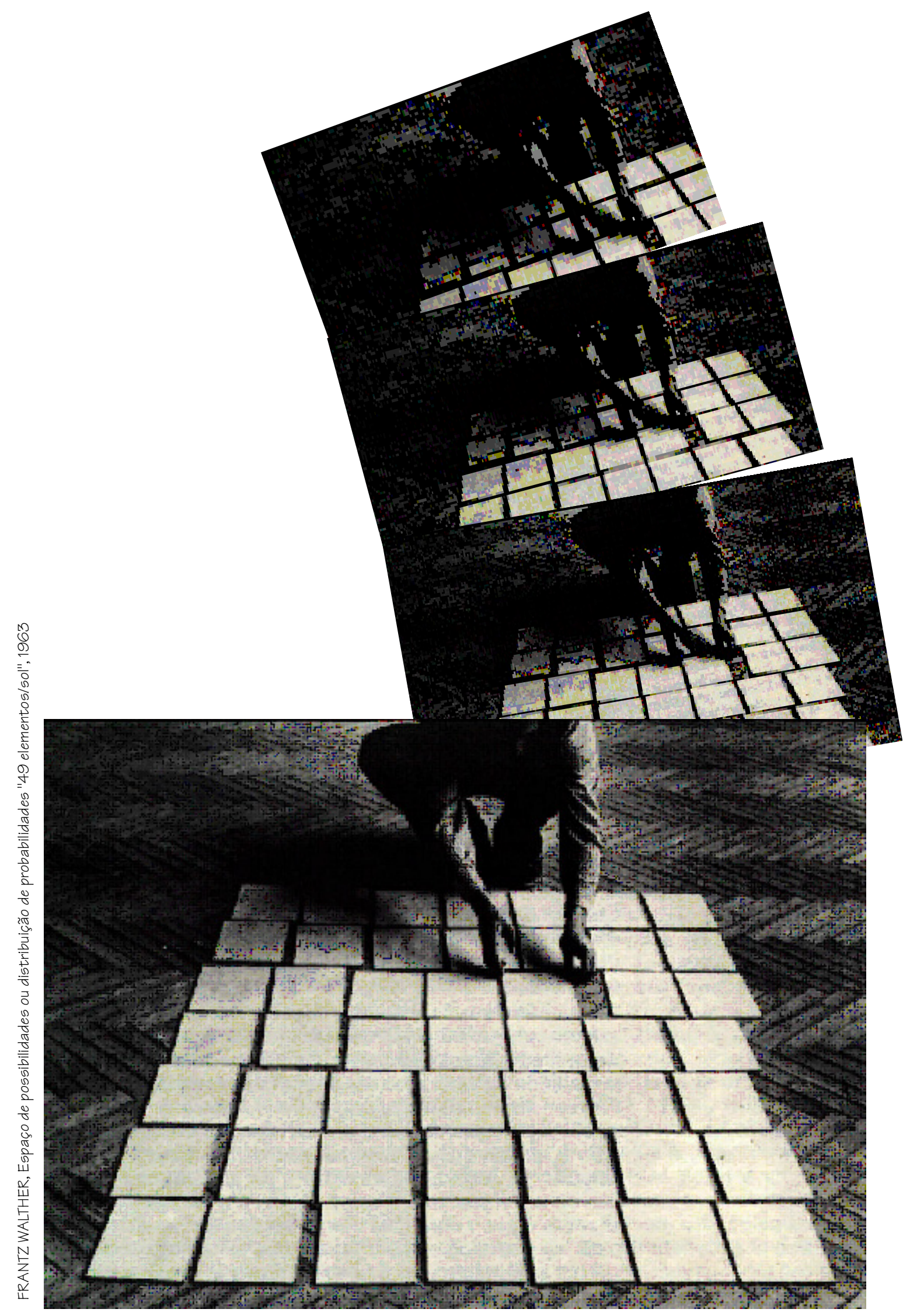

166 Interface - Comunic, Saúde, Educ 4 